\title{
The Impact of Crossgroup Friendships in South Africa: Affective Mediators and Multigroup Comparisons
}

\author{
Hermann Swart* \\ University of Stellenbosch
}

\author{
Miles Hewstone \\ University of Oxford
}

Oliver Christ

Philipps-University Marburg

\author{
Alberto Voci \\ University of Padova
}

Two cross-sectional survey studies among majority-status White and minoritystatus Coloured high school students in South Africa explored the effects of crossgroup friendships on prejudice, and the affective processes (intergroup anxiety in Study 1, and intergroup anxiety and affective empathy in Study 2) underlying these effects with respect to two target groups for each sample. Crossgroup friendships were negatively associated with negative action tendencies, and positively associated with positive outgroup attitudes and greater perceived outgroup variability for both samples, irrespective of the target group. The importance of intergroup anxiety and affective empathy as mediators of these effects was also confirmed. Multigroup comparisons showed significant differences in the structural models across the two samples in both studies, and confirmed prior findings in the contact literature that contact effects are stronger for majority than minority groups. These findings are the first of their kind within the South African context.

\footnotetext{
* Correspondence concerning this article should be addressed to Dr. Hermann Swart, Department of Psychology, University of Stellenbosch, Private Bag X1, Matieland, 7602, South Africa [e-mail: hswart@sun.ac.za].
} 
The contact hypothesis (Allport, 1954) - that positive intergroup contact reduces prejudice-has received substantial empirical support (for a meta-analytic review see Pettigrew \& Tropp, 2006). Contemporary research on intergroup contact has (1) highlighted the importance of crossgroup friendship as a dimension of contact (e.g., Mendoza-Denton \& Page-Gould, 2008; Page-Gould, MendozaDenton, \& Tropp, 2008; Pettigrew, 1997; Pettigrew \& Tropp, 2006; for a review see Turner, Hewstone, Voci, Paolini, \& Christ, 2008), (2) emphasized the role of affective processes (e.g., intergroup anxiety and empathy/perspective taking) in the contact-prejudice relationship (Pettigrew \& Tropp, 2008), and (3) established that contact effects appear to be stronger for majority than minority group members (Tropp \& Pettigrew, 2005).

The present research explored the effects of crossgroup friendships on prejudice in South Africa, paying attention to the mediational role of intergroup anxiety and affective empathy. This research had three aims. First, we explored the effects of crossgroup friendship in the context of intergroup relations in South Africa. Second, we sought to provide a more differentiated understanding of the complex processes underlying this form of intergroup contact by considering the effects of both positive and negative affective mediators on affective, quasi-behavioral, and cognitive measures of prejudice. Third, we compared the contact-prejudice relationship (and its underlying processes) across two groups differing in status.

\section{Crossgroup Friendships}

Although the focus on crossgroup friendship as a potent dimension of intergroup contact is only quite recent (e.g., Mendoza-Denton \& Page-Gould, 2008; Page-Gould et al., 2008; Pettigrew, 1997, 1998; Pettigrew \& Tropp, 2006), the importance of creating contact that is "intimate" or has "acquaintance potential" has long been recognized in the literature (e.g., Allport, 1954; Amir, 1969). In their meta-analysis, Pettigrew and Tropp (2006) reported a significantly stronger $(p<.05)$ contact-prejudice relationship in 154 tests that included crossgroup friendships as a measure of contact (mean $r=-.25$ ) than in 1,211 tests that did not (mean $r=-.21$ ).

The intimate nature of the contact between friends has generally been regarded as being of better quality than casual, superficial contact (Allport, 1954; Pettigrew, 1997, 1998). Pettigrew (1998) and Pettigrew and Tropp (2006) suggest that friendships generally involve three of Allport's (1954) optimal contact conditions (equal status contact, common interests/goals, and cooperation) and, moreover, such contact occurs over an extended period of time, involving frequent contacts in a variety of settings. Indeed, previous studies have shown that crossgroup friendships have stronger effects on prejudice than do other forms of contact, such as that between neighbors or work colleagues (Hamberger \& Hewstone, 1997; Pettigrew, 1997; Pettigrew \& Tropp, 2006). This stronger effect is ascribed, 
in part, to the affective ties (including the simultaneous reduction of negative affect, such as intergroup anxiety, and increased positive effect, such as affective empathy) that are established between crossgroup friends (Pettigrew, 1998), to which we now turn.

\section{Affective Mediators of Contact}

Intergroup anxiety and empathy/perspective taking are the two most commonly researched affective mediators in the contact literature (see Pettigrew \& Tropp, 2008). Intergroup anxiety (Stephan \& Stephan, 1985) is the anxiety individuals (as ingroup members) experience when anticipating a future encounter with one or more outgroup members and is likely to occur in contexts characterized by intergroup conflict or minimal previous intergroup contact. Such intergroup anxiety may lead to contact avoidance, among others (see Stephan \& Stephan, 1985). Intergroup anxiety is regarded as one of the most important affective mediators of the contact-prejudice relationship (Brown \& Hewstone, 2005). Recent evidence from experimental (e.g., Page-Gould et al., 2008), cross-sectional (e.g., Paolini, Hewstone, Cairns, \& Voci, 2004; Vonofakou, Hewstone, \& Voci, 2007), and longitudinal (e.g., Levin, van Laar, \& Sidanius, 2003) studies confirms that crossgroup friendships are associated with a reduction in intergroup anxiety, while intergroup anxiety discourages the establishment of crossgroup friendships.

Since Davis' (1994) classic work, empathy has been understood as comprising both an affective response to the emotional state of another (e.g., Batson et al., 1997), and, more cognitively, as the ability to take another person's perspective (e.g., Galinsky \& Moskowitz, 2000). Both the affective and the cognitive empathic responses have been associated with numerous positive outcomes, including an increased tolerance for other groups and an increased concern for the well-being of others (e.g., Batson et al., 1997; Galinsky \& Moskowitz, 2000). Positive intergroup contacts have been associated with increased empathy/perspective taking, which has in turn been associated with reduced outgroup prejudice (e.g., Turner, Hewstone, \& Voci, 2007). The ability to "put yourself in the shoes" of an outgroup member (emotionally and/or cognitively) holds important benefits for intergroup relations. These benefits are capable of lasting well after the initial empathic response has dissipated (e.g., Batson, Turk, Shaw, \& Klein, 1995), and are capable of generalizing to the outgroup as a whole, and to uninvolved outgroups (e.g., Galinsky \& Moskowitz, 2000).

Pettigrew and Tropp (2008) undertook a meta-analysis comparing the mediating effects of both intergroup anxiety and empathy/perspective taking (as well as outgroup knowledge). While all three constructs were significant mediators of contact effects, intergroup anxiety showed the strongest mediational effects, followed by empathy/perspective taking, and outgroup knowledge, respectively. These findings emphasize the relative importance of the affective (as opposed 
to cognitive) processes underlying the contact-prejudice relationship (Pettigrew, 1998).

\section{Group Status and Contact Effects}

Recent evidence suggests that minority- and majority-status group members enter contact situations with differing expectations and objectives (Tropp, 2006). Where minority group members may fear being the targets of prejudice, majority group members are often concerned about being perceived as prejudiced by minority group members (see Vorauer, Main, \& O'Connell, 1998). The heightened awareness of status differences beyond the contact setting among minority group members is likely to limit the benefits of positive contact experiences for them, irrespective of the positive nature of the contact setting (Tropp, 2006).

Tropp and Pettigrew (2005) undertook a metaanalysis exploring contact effects as a function of group status and found that contact-prejudice relationships were significantly stronger $(p<.01)$ for majority (mean $r=-.24)$ than minority (mean $r=-.18$ ) samples. Thus, to the extent that such contact experiences leave the illegitimate status differences unaddressed or unaltered (Saguy, Dovidio, \& Pratto, 2008) and the minority group reminded of their devalued status (Tropp, 2006), positive (even optimally structured) contact experiences may be more beneficial for majority groups than for minority groups.

\section{The South African Context}

South Africa's 45 million people comprise approximately $79 \%$ Blacks, $9.5 \%$ Whites, 9\% Coloureds (person's of mixed racial heritage), and 2.5\% of Indian descent (Statistics South Africa, 2004). These groups are not uniformly distributed across the country. In the region (the Western Cape Province) and the town (Stellenbosch) in which the present research was undertaken, Blacks (approx. 27.00\%) are underrepresented, while Coloureds (approx. 55\%) and Whites (approx. 18\%) are overrepresented (Statistics South Africa, 2004).

The legacy of apartheid's racial categories persists within contemporary South Africa (Pillay \& Collings, 2004). While the political power has shifted from the Whites to the Blacks, Whites generally enjoy a socioeconomic advantage over Blacks and Coloureds. The intermediate (marginalized) group status of Coloureds has remained unchanged (Grossberg, 2002). Intergroup relations in South Africa are characterized by limited intergroup contact, continued segregation, a sense of discomfort, and mistrust (Durrheim \& Dixon, this issue; Gibson, 2004; Hofmeyr, 2006). In a recent survey among nationally representative samples, large proportions of the respondents across all population groups reported having no outgroup friends and found it hard to imagine ever having an outgroup friend (Gibson, 2004). 
More encouragingly, where positive intergroup contacts are reported, they are associated with positive intergroup attitudes (e.g., Dixon et al., this issue; Tredoux \& Finchilescu, this issue). Within the context of the present research, one may expect that such contact-prejudice relationships will be stronger for Whites than for Coloureds. The burden of being reminded of their devalued status (or the expectation of such reminders) is thought to limit the benefits of positive contact experiences for minority groups (Tropp, 2006), such as Coloureds. Conversely, to the extent that Whites as a majority group are not encumbered by this burden, contact-prejudice relationships would be expected to be stronger for Whites than for Coloureds. So, even if Coloureds are engaged with Blacks (a relative socioeconomic, and numerical, minority group-particularly in the Western Cape Province, where this research was undertaken), their marginal status in South Africa could inhibit the strength of the contact-prejudice relationships as compared to what one would expect for Whites interacting with Blacks. However, it is possible that, since Whites and Coloureds may both be considered majority groups relative to Blacks, the contact-prejudice relationships should not differ significantly between Whites and Coloureds when they interact with the Black outgroup. We test these alternatives in the research reported below.

The town of Stellenbosch lies approximately 60 kilometers East of Cape Town. Its 120,000 residents reside in residential areas that have remained, by and large, racially homogeneous. White residential areas are more affluent than the Coloured residential areas, which, in turn, are more affluent than the Black residential area (that comprises low-cost and informal housing), mirroring the differences in socioeconomic status across these groups. In Stellenbosch (as in many parts of South Africa), Whites may be considered a majority-status group relative to Blacks. Coloureds may be regarded as a minority-status group relative to Whites, but (arguably) a majority-status group relative to Blacks.

\section{The Present Research}

The reported research addresses four gaps identified in the contact literature: (1) no South African contact literature (of which we know) has explored the affective processes underlying the relationship between crossgroup friendships and prejudice; (2) the literature simultaneously comparing contact effects across majority- and minority-status groups is limited; (3) as is the literature exploring simultaneously the positive and negative affective mediators of contact; (4) scant research attention has been given to affective empathy (as opposed to perspective taking) as a mediator of contact effects.

We explored the effects of crossgroup friendship on affective, quasibehavioral, and cognitive measures of prejudice in two studies among White and Coloured Grade 11 and 12 South African high school students (approx. 16 to 18 years of age) from two high schools, one a predominantly White, boys-only 
school (approx. 85\% White, 10\% Coloured, and 5\% Black students), the other a predominantly Coloured, coeducational high school (approx. 90\% Coloured and $10 \%$ Black students). We investigated intergroup anxiety (in studies 1 and 2) and affective empathy (in Study 2 only) as potential mediators between contact and outcomes, and multigroup comparisons explored the relationships between the variables as a function of group status.

\section{Method}

\section{Questionnaire}

The data for both studies were collected using a survey comprising two broad sections. One section focused its questions on the Black outgroup as the target group for both White and Coloured participants (Study 1), the other focused its questions on the Coloured outgroup as the target group for White participants, and the White outgroup as the target group for Coloured participants (Study 2). Thus, wherever the word "outgroup" appears in the question descriptions below, the word "Black(s)", "Colored(s)", or "White(s)" was used in the actual questionnaire depending upon whether the questionnaire formed part of study 1 or study 2 , and depending upon the participants completing the questionnaire. Both sections were presented to each participant, with the order counterbalanced across participants.

The measures included in Study 1 included items assessing crossgroup friendships as a predictor variable, intergroup anxiety as a mediator variable, and outgroup attitudes and perceived outgroup variability as the two outcome variables. These predictor, mediator, and outcome measures were retained for Study 2 (albeit focusing on different target groups), with the addition of two further measures, namely affective empathy as an additional mediator and negative action tendencies as an additional outcome variable. These two measures were omitted from Study 1 to limit the overall survey length. Prior to completing the survey, participants provided biographical information regarding their age, gender, and population group (White, Black, Coloured, Indian, or other).

Predictor. A two-item measure of crossgroup friendship assessed the number of outgroup friends, scaled from 0 (none) to 4 (more than ten), and the amount of time spent with outgroup friends, scaled from 0 (never) to 4 (all the time).

Mediator(s). A six-item measure of intergroup anxiety (based on Stephan \& Stephan, 1985) asked participants how they would feel if interacting with unknown outgroup peers (ratings were made on six bipolar adjectives: nervous/relaxed, worried/pleased, scared/not scared, awkward/at ease, defensive/open, and unconfident/confident, all scaled from $1=$ not at all to $5=$ very much). A three-item measure of affective empathy (included in Study 2 only; Batson et al., 1997; Davis, 1994) asked participants to indicate the extent to which they would "feel upset" 
if they saw an outgroup person "suffering in some way," "feel angry" if they saw an outgroup person "being treated unfairly," and "feel sad" if an outgroup person they knew "were feeling sad" (all scaled from $1=$ not at all to $5=$ very much).

Outcomes. A four-item measure of outgroup attitudes (based on Wright, Aron, McLaughlin-Volpe, \& Ropp, 1997) asked participants to rate their feelings toward outgroup people on four bipolar adjectives (warm/cold, friendly/hostile, respect/contempt, and admiration/disgust; all scaled from $1=$ not at all to $5=$ very much). A three-item measure of perceived outgroup variability (adapted from Kashima \& Kashima, 1993) asked participants to rate the extent to which they believed outgroup people in general "are all the same," "have similar views and opinions," and "all behave in the same way" (all scaled from $1=$ very much the same to $5=$ very different from one another). A three-item measure of negative action tendencies (based on Mackie, Devos, \& Smith, 2000; included in Study 2 only) asked participants to indicate the extent to which they would like to engage in negative behaviors ("argue with," "fight with," and "stand up to"; all scaled from $1=$ not at all to $5=$ very much) toward outgroup people in general. All measures were scored such that higher mean scores denote higher levels of a particular construct (including more positive outgroup attitudes and greater perceived outgroup variability).

\section{Procedure}

The headmaster at each school, acting in loco parentis, gave consent for the students' participation in this research. The survey was administered during a regular class period. Participants were assured that their responses would be confidential and anonymous and were allowed to withdraw from the survey at any time, if they wished; none did. They were given detailed instructions for completing the survey and were debriefed afterwards.

Only the surveys of those participants who identified themselves as "White" at the "White" high school or as "Coloured" at the "Coloured" high school were included in studies 1 and 2. Surveys returned by 9 Black, 16 Coloured, and 3 other participants from the "White" high school, and returned by 14 Black and 2 other participants from the "Coloured" high school, were excluded. Although the majority of participants managed to complete questions for both studies during the time available, many participants only managed to complete questions relating to the study that was presented to them first (given the counterbalanced presentation of the questions, these questions related either to Study 1 or Study 2). A multivariate analysis of variance (MANOVA) showed no significant differences between the mean scores for those participants who only managed to complete the questions for either Study 1 or Study 2 in the available time and those participants who managed to complete the questions for both studies (all $p$ values $>.05$ ). These findings do not support the possibility of selection bias among the participants with respect to 
the manner in which they answered the questions. The data analyzed for Study 1 therefore included all those participants who completed Study 1 (irrespective of whether they also completed Study 2 or not) while the data analyzed for Study 2 included all those participants who completed Study 2 (irrespective of whether they also completed Study 1 or not).

\section{Study 1}

This study investigated intergroup anxiety as a mediator of the effect of crossgroup friendship on outgroup attitudes and perceived outgroup variability. The structural relationships between the different variables across the White and Coloured samples were compared using structural equation modeling (SEM) with latent constructs. The target group for both samples was the Black outgroup. The final samples comprised 186 White male participants: Mean age $=16.83$ years $(S D=0.71)$, and 196 Coloured participants (74 males and 122 females): Mean age $=16.98$ years $(S D=0.96)$.

\section{Predictions}

We tested four predictions for both White and Coloured samples: (1) crossgroup friendships with members of the Black outgroup will be positively associated with (positive) outgroup attitudes toward the Black outgroup; (2) crossgroup friendships will be positively associated with greater perceived outgroup variability of the Black outgroup; (3) both these relationships will be mediated by intergroup anxiety; specifically, crossgroup friendships will be negatively associated with intergroup anxiety that, in turn, will be negatively associated with both outgroup attitudes and perceived outgroup variability; (4) the contact-prejudice relationships described above will be significantly stronger for the majority-status Whites than for the minority-status Coloureds.

\section{Results}

\section{Preliminary Data Analyses}

The correlations between the composite measures, and their reliability coefficients, means, and standard deviations $(S D)$ are summarized in Table 1 for both samples. Exploratory factor analyses (EFA; maximum likelihood [ML] estimator) confirmed that each construct was unidimensional for each sample. On the mean level, Whites reported significantly fewer crossgroup friends, $t(380)=-4.41, p<$ .001 , significantly less positive outgroup attitudes, $t(380)=-8.95, p<.001$, a significantly lower perception of outgroup variability, $t(380)=-2.90, p<.01$, and significantly more intergroup anxiety with regards to the Black outgroup, 
Table 1. Pearson Product-Moment Correlations between Composite Variables, Construct Reliability, Means, and $S D$ (Study 1)

\begin{tabular}{|c|c|c|c|c|c|c|}
\hline & \multirow[b]{2}{*}{1} & \multirow[b]{2}{*}{2} & \multirow[b]{2}{*}{3} & \multirow[b]{2}{*}{4} & \multicolumn{2}{|c|}{ Coloured Sample } \\
\hline & & & & & $\begin{array}{l}\text { Reliability } \\
(\alpha)\end{array}$ & $\begin{array}{c}\text { Means } \\
(S D)\end{array}$ \\
\hline 1. Crossgroup friendships & - & $-.33^{* *}$ & $.33^{* *}$ & $.19^{* *}$ & .84 & $1.03(1.02)$ \\
\hline 2. Intergroup anxiety & $-.44^{* *}$ & - & $-.29 * *$ & $-.22 * *$ & .89 & $2.57(1.05)$ \\
\hline 3. Outgroup attitudes & $.40^{* *}$ & $-.55^{* *}$ & - & $.28 * *$ & .75 & $3.54(0.90)$ \\
\hline 4. Perceived variability & $.24^{* *}$ & $-.36^{* *}$ & $.53^{* *}$ & - & .70 & $3.42(0.96)$ \\
\hline \multicolumn{7}{|l|}{ White Sample } \\
\hline Reliability $(\alpha)$ & .78 & .93 & .85 & .85 & & \\
\hline Means $(S D)$ & $0.61(0.84)$ & $3.38(1.08)$ & $2.75(0.90)$ & $3.09(1.22)$ & & \\
\hline
\end{tabular}

Note. Correlations between measures for the Coloured participants are reported above, and similar correlations for White participants are reported below, the diagonal.

$* * p<.01$.

$t(380)=7.36, p<.001$, than did the Coloured respondents. Thus, on the mean (group) level, the Coloured participants responded significantly more favorably toward the Black outgroup than did the White participants. The overall pattern (i.e., sign) of the relationships between the composite measures (Table 1) was identical for both samples, although the correlations were noticeably larger for the White sample than for the Coloured sample. A one-way analysis of variance (ANOVA) showed no significant differences between the mean scores of Coloured male and female participants (all $p$ values $>.05$ ).

\section{SEM with Latent Constructs}

The structural relationships between the variables were investigated separately for each sample via SEM with latent constructs (Mplus v3.11; Muthén \& Muthén, 2005). The individual items used to measure each latent construct, excluding intergroup anxiety, served as manifest indicators for their respective latent construct. From the six indicators used to measure the latent construct of intergroup anxiety we created three parcels of two items per parcel using the itemto-construct method (Little, Cunningham, Shahar, \& Widaman, 2002). Identical parcels were constructed for the intergroup anxiety construct for both samples (allowing for further group comparisons).

We used a two-step approach to SEM. In the first step, we tested the measurement model and then proceeded to test the structural model in the second step (see Anderson \& Gerbing, 1988). The measurement model (robust maximum likelihood [MLR] estimates) showed adequate model fit for both the White, $\chi^{2}(48)=105.441, p<.001$; a Comparative Fit Index $(\mathrm{CFI})=.942$; a root mean 
square error of approximation (RMSEA) $=.080$; and a standardized root mean square residual $(\mathrm{SRMR})=.059$, and Coloured samples, $\chi^{2}(48)=76.636, p<$ .01 ; CFI $=.960$; RMSEA $=.055$; SRMR $=.051$, confirming the discriminant validity of each construct for both samples. The criteria for acceptable model fit for these goodness-of-fit indices were defined by CFI $\geq .90$, RMSEA $<.08$, and SRMR $<.08$ (Hu \& Bentler, 1999).

We then examined the extent of measurement invariance for the measurement model across the two samples using multiple group analysis. This is a necessary precondition prior to any further meaningful group comparisons relating to the structural relationships between the latent constructs (Vandenberg \& Lance, 2000). There are different forms of measurement invariance that differ in terms of parameter constraints. Comparing structural paths in SEM requires at least metric invariance (Byrne, Shavelson, \& Muthén, 1989). We compared the measurement model across the two samples using the goodness-of-fit indices of various models, varying in parameter constraints relating to the factor loadings (e.g., in one model the factor loadings were allowed to be freely estimated across samples, while in another they were constrained to equality across samples). These models were compared to one another using a scaled chi-square difference test (Satorra \& Bentler, 1999). The measurement model specifying full metric invariance (i.e., where the factor loadings were constrained to equality) across both samples showed good model fit, $\chi^{2}(112)=204.065, p<.001 ; \mathrm{CFI}=.946$; RMSEA $=.066$; SRMR $=$ .062 , and did not show a significantly worse fit than the baseline model specifying freely estimated parameters.

In the second step, we tested the structural model for both the White and Coloured samples (Figure 1). The model fit indices for both samples ranged from adequate to good. Structural invariance was assessed in a similar fashion to that of measurement invariance above (except the parameter constraints involved here related to the path coefficients between the constructs as opposed to the factor loadings). A model specifying partial structural invariance (with a significant difference existing only in the path from crossgroup friendships to intergroup anxiety) produced the best model fit, $\chi^{2}(117)=214.957, p<.001$; CFI $=$ .943 ; RMSEA $=.066$; SRMR $=.086$. Thus, the structural models for the White and Coloured samples are considered equivalent along all the structural paths, except the path from crossgroup friendships to intergroup anxiety, which was significantly larger $(p<.05)$ for Whites $(b=-.71)$ than for Coloureds $(b=-.38$; see Figure 1).

\section{Mediation Effects}

For the White sample, the significant direct path between crossgroup friendship and outgroup attitudes remained $(b=.30, p<.05)$, even when the effects of all other variables were controlled for. Intergroup anxiety partially mediated the total effect of crossgroup friendships on outgroup attitudes: crossgroup friendship 


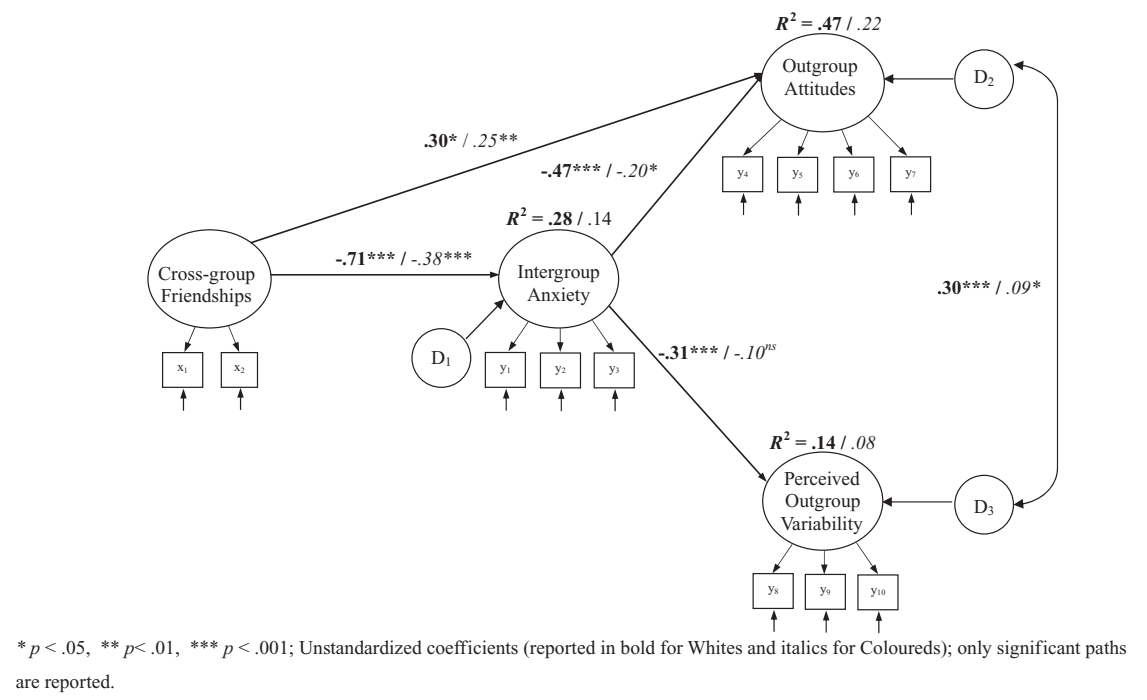

Fig. 1. Structural equation model of the effects of crossgroup friendship on outgroup attitudes toward, and perceived outgroup variability of, Blacks among White (bold) and Coloured (italics) high school students, showing mediation via intergroup anxiety (Study 1).

was negatively associated with intergroup anxiety $(b=-.71, p<.001)$, which, in turn, was negatively associated with outgroup attitudes $(b=-.47, p<.001)$. A Sobel test (Baron \& Kenny, 1986; Sobel, 1982) confirmed that this partial mediation was significant $(z=3.76, p<.001)$.

When controlling for the effects of all the other variables, the initial positive relationship between crossgroup friendships and perceived outgroup variability (see Table 1) was reduced to nonsignificance. Crossgroup friendships did, however, have an indirect effect on perceived outgroup variability via intergroup anxiety, with a negative relationship with intergroup anxiety (reported above) that, in turn, was negatively associated with perceived outgroup variability $(b=-.31, p<.001)$. A Sobel test confirmed that this full mediation of crossgroup friendship effects on perceived outgroup variability by intergroup anxiety was significant $(z=2.84$, $p<.01)$. This model explained $47 \%$ and $14 \%$ of the variance in the outcome measures (outgroup attitudes and perceived outgroup variability, respectively).

The results were comparable for the Coloured sample. The significant path between crossgroup friendships and outgroup attitudes remained $(b=.25, p<$ $.01)$ after the effects of all other variables were accounted for. Intergroup anxiety partially mediated the total effect of crossgroup friendships on outgroup attitudes: crossgroup friendships were negatively associated with intergroup anxiety $(b=$ $-.38, p<.001)$, which, in turn, was negatively associated with outgroup attitudes $(b=-.20, p<.05)$. A Sobel test confirmed that this partial mediation was significant $(z=2.14, p<.05)$. When controlling for the effects of all the other 
variables, crossgroup friendships had neither a significant direct nor indirect effect on perceived outgroup variability for the Coloured sample. This model explained $22 \%$ and $8 \%$ of the variance in the outcome measures (outgroup attitudes and perceived outgroup variability, respectively).

Although the data fit the hypothesized model well (consistent with causation from crossgroup friendships to reduced prejudice, via intergroup anxiety, as predicted by the contact hypothesis), cross-sectional data are not suited for causal analyses (MacCallum \& Austin, 2000), and alternative (equivalent) models (MacCallum, Wegener, Uchino, \& Fabrigar, 1993) may exist that describe the data equally well. We tested various alternative models and found three equivalent models, suggesting three alternative explanations for the relationships between the variables, two of which support the reverse causal direction, from prejudice to contact (i.e., selection bias-that individuals with reduced prejudice will engage in more intergroup contact). Thus, while it does appear that crossgroup friendships improve outgroup attitudes and perceptions of outgroup variability via the reduction of intergroup anxiety, the effects of selection bias cannot be discounted.

\section{Study 2}

This study explored a central feature of crossgroup friendships, as proposed by Pettigrew (1998), namely that such friendships are capable of simultaneously reducing negative affect and increasing positive affect toward outgroup members. We explored the simultaneous effects of a negative (intergroup anxiety) and a positive (affective empathy) affective mediator on the relationship between crossgroup friendship and various measures of prejudice, overcoming one of the shortcomings of Study 1, which only included a negative affective mediator (intergroup anxiety). In addition, we added a quasibehavioral criterion variable (negative action tendencies; Mackie et al., 2000) to the two criterion variables measured in Study 1 to explore the simultaneous effects of crossgroup friendships on a broader range of prejudice measures (Brown \& Hewstone, 2005). We computed multigroup comparisons, comparing the structural relationships between the variables across the two samples. The outgroups for this study were the Coloured outgroup (for the White participants) and the White outgroup (for the Coloured participants). The White sample comprised 171 male participants: Mean age $=16.80$ years $(S D=$ 0.71), and the Coloured sample comprised 191 participants (73 males and 118 females); Mean age $=16.92$ years $(S D=0.91)$.

\section{Predictions}

We tested six predictions for both the White and Coloured samples: Crossgroup friendship will have (1) a positive association with outgroup attitudes and (2) with perceived outgroup variability; (3) a negative association with negative action 
tendencies; (4) intergroup anxiety will mediate the various contact-prejudice relationships: specifically, crossgroup friendship will be negatively associated with intergroup anxiety that will, in turn, be negatively associated with outgroup attitudes and perceived outgroup variability, and positively associated with negative action tendencies. (5) Affective empathy will mediate the various contact-prejudice relationships: specifically, crossgroup friendship will be positively associated with affective empathy that will, in turn, be positively associated with outgroup attitudes and perceived outgroup variability, and negatively associated with negative action tendencies. (6) The contact-prejudice relationships described above will be significantly stronger for the majority-status White than for the minority-status Coloured sample.

\section{Method}

\section{Questionnaire and Procedure}

The constructs that were assessed included a two-item measure of crossgroup friendships as a predictor variable, a six-item measure of intergroup anxiety and a three-item measure of affective empathy as the mediator variables, and a fouritem measure of outgroup attitudes, a three-item measure of perceived outgroup variability, and a three-item measure of negative action tendencies as the outcome variables (each described earlier).

\section{Results}

\section{Preliminary Data Analyses}

The correlations between the composite measures, and their reliability coefficients, means and $S D$ are shown in Table 2 for both samples. An EFA (ML estimator) confirmed that each construct was unidimensional for each sample. On the mean level, White respondents reported significantly more Coloured crossgroup friendships, $t(360)=2.65, p<.01$, higher intergroup anxiety, $t(360)=$ $10.74, p<.001$, and more negative action tendencies, $t(360)=4.72, p<.001$, and significantly less positive outgroup attitudes $t(360)=-5.43, p<.001$, and perceived outgroup variability, $t(360)=-3.49, p<.01$, with regards to the Coloured outgroup than did the Coloured sample with regards to the White outgroup. There was no significant difference between the two samples with respect to affective empathy, $t(360)=0.55, p>.05$. Thus on the mean level, the Coloured participants responded significantly more favorably toward the White outgroup than did the White participants toward the Coloured outgroup.

One-way ANOVAs of mean scores showed that Coloured male participants reported significantly more crossgroup friendships, $F(1,189)=5.83, p<.05$, 


$$
\text { 貝 }
$$


affective empathy, $F(1,189)=8.44, p<.01$, perceived outgroup variability, $F(1$, $189)=6.39, p<.05$, and negative action tendencies, $F(1,189)=12.50, p<.01$, than did Coloured female respondents.

\section{SEM with Latent Constructs}

SEM with latent constructs (Mplus v3.11; Muthén \& Muthén, 2005) was used to explore the structural relationships between the predictor, mediator, and criterion variables. The individual items used to measure each latent construct, excluding intergroup anxiety, served as manifest indicators for their respective latent construct. From the six indicators used to measure intergroup anxiety we created three parcels of two items per parcel using the item-to-construct method (Little et al., 2002).

As in Study 1, we used the two-step approach to SEM recommended by Anderson and Gerbing (1988) by testing the measurement model in the first step, and then the structural model in the second step for each sample. In the first step, a CFA (MLR estimator) showed good model fit on the measurement level for both the White, $\chi^{2}(120)=171.984, p<.01$; CFI $=.953$; RMSEA $=.050$; $\mathrm{SRMR}=.056$, and Coloured samples, $\chi^{2}(120)=117.776, p<.05 ; \mathrm{CFI}=1.00 ;$ $\mathrm{RMSEA}=0.000 ; \mathrm{SRMR}=.048$, confirming the discriminant validity of each of the constructs for each sample. A model specifying metric invariance between the two samples produced the best model fit, $\chi^{2}(253)=311.238, p<.01$; CFI $=$ $.969 ; \mathrm{RMSEA}=.036 ; \mathrm{SRMR}=.059$. This model fit was not significantly worse than the baseline model specifying freely estimated parameters when compared using the scaled chi-squared difference test (Satorra \& Bentler, 1999).

In the second step, we created structural path models for both the White and Coloured samples (Figure 2). The model fit for the White sample was good while for the Coloured sample it was excellent. The two structural models varied markedly from one another; a model specifying four paths that differed significantly across the two groups yielded the best model fit, $\chi^{2}(264)=325.315, p<$ $.01 ; \mathrm{CFI}=.967 ; \mathrm{RMSEA}=.036 ; \mathrm{SRMR}=.066$. These results suggest large-scale structural differences in the structural models across the two samples (along the paths between crossgroup friendships and intergroup anxiety, intergroup anxiety and negative action tendencies, crossgroup friendships and affective empathy, and crossgroup friendships and perceived outgroup variability).

The direct path from crossgroup friendships to perceived outgroup variability is omitted from Figure 2 as it was nonsignificant for both samples (and only significant paths are reported). The path between these two constructs differed significantly for the two samples with respect to their nonsignificance (i.e., it was significantly more nonsignificant for the Coloured sample than for the White sample). 


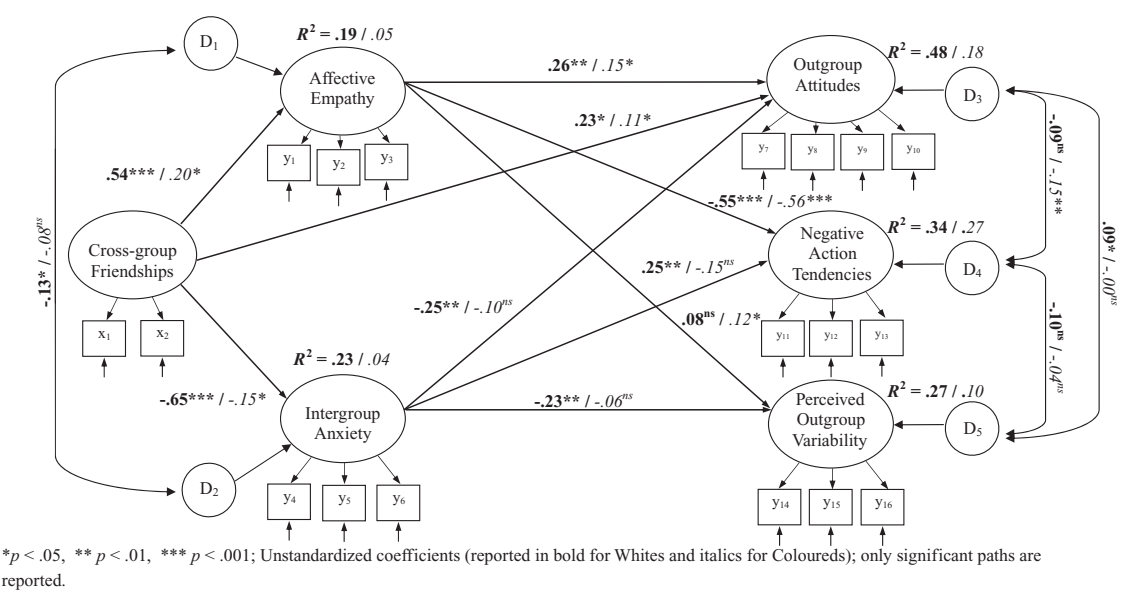

Fig. 2. Structural equation model of the effects of crossgroup friendship on outgroup attitudes and negative action tendencies toward, and perceived outgroup variability of, Coloureds/ Whites among White (bold) and Coloured (italics) high school students, showing mediation via intergroup anxiety and affective empathy (Study 2).

\section{Mediation Effects}

Among the White participants, crossgroup friendships had a significant, direct, positive effect on outgroup attitudes $(b=.23, p<.05)$, even after controlling for the effects of all the other variables on outgroup attitudes. Affective empathy and intergroup anxiety partially mediated the total effect of crossgroup friendships on outgroup attitudes: crossgroup friendships had a significant positive relationship with affective empathy $(b=.54, p<.001)$ that, in turn, had a significant positive relationship with outgroup attitudes $(b=.26, p<.01)$; and crossgroup friendships was negatively associated with intergroup anxiety $(b=-.65, p<$ $.001)$ that, in turn, had a significant negative relationship with outgroup attitudes $(b=-.25, p<.01)$. Sobel tests of these indirect effects confirmed that the partial mediation by affective empathy $(z=2.44, p<.05)$ and intergroup anxiety $(z=$ $2.68, p<.01)$ was significant. Crossgroup friendship had a significant indirect effect on negative action tendencies via both affective empathy and intergroup anxiety: crossgroup friendships had a significant positive relationship with affective empathy (as reported above) that, in turn, had a significant negative relationship with negative action tendencies $(b=-.55, p<.001 ; z=3.16, p<.01)$; and crossgroup friendships was negatively associated with intergroup anxiety (as reported above) that, in turn, had a significant positive association with negative action tendencies $(b=.25, p<.01 ; z=2.27, p<.05)$. Finally, intergroup anxiety significantly, and fully, mediated the total effect of crossgroup friendships on perceived 
outgroup variability: crossgroup friendships had a significant negative association with intergroup anxiety (as reported earlier) that, in turn, had a significant negative association with perceived outgroup variability $(b=-.23, p<.01 ; z=2.39, p<$ $.05)$. While the direct relationship between crossgroup friendships and perceived outgroup variability was in the predicted direction, it only approached significance $(b=.23, p=.10)$.

The structural model for the White sample explained a substantial proportion of the variance in all three outcome measures (outgroup attitudes: 48\%; negative action tendencies: $34 \%$; perceived outgroup variability: $27 \%$ ).

For the Coloured sample, the structural relationships between the latent variables were markedly different from those reported for the White sample. Crossgroup friendships had a significant, direct, positive association with outgroup attitudes once all the other variables had been controlled for $(b=.11, p<.05)$. Affective empathy partially mediated this effect of crossgroup friendships on outgroup attitudes: crossgroup friendships had a significant positive association with affective empathy $(b=.20, p<.05)$ that, in turn, had a significant positive association with outgroup attitudes $(b=.15, p<.05)$. A Sobel test of this indirect effect showed this partial mediation approached significance $(z=1.70, p<.09)$. Furthermore, crossgroup friendships had a significant indirect effect on negative action tendencies and a marginally significant indirect effect on perceived outgroup variability: crossgroup friendships had a significant positive association with affective empathy (as reported above) that, in turn, had a significant negative association with negative action tendencies $(b=-.56, p<.001 ; z=2.15, p<.05)$, and a significant positive association with perceived outgroup variability $(b=.12$, $p<.05 ; z=1.55, p=.12$ ). Although crossgroup friendships were significantly negatively associated with intergroup anxiety $(b=-.15, p<.05)$, intergroup anxiety was not significantly associated with any of the three outcome measures of prejudice. The structural model for the Coloured sample explained less variance for each of the outcome variables compared to that of the White sample (outgroup attitudes: $18 \%$; negative action tendencies: $27 \%$; perceived outgroup variability: $10 \%)$.

We tested various alternative models and found three competing explanations (equivalent models) for the interactions between the variables. Two of these alternative models suggested that the data may be equally well described by a model where initial prejudice influences the development of crossgroup friendships (i.e., selection bias; as in Study 1). Although the data fit the hypothesized model well (Figure 2; consistent with causation from crossgroup friendships to reduced prejudice, via intergroup anxiety and affective empathy, as predicted by the contact hypothesis), these findings urge caution in drawing causal conclusions (even implicitly via model construction) when relying on crosssectional data. 


\section{General Discussion}

The present research aimed to explore the mediation of crossgroup friendship effects on affective, cognitive, and quasibehavioral measures of prejudice within the context of South African intergroup relations, and to explore these effects across two samples differing in group status, namely majority-status Whites and minority-status Coloureds. In Study 1, crossgroup friendships with Blacks were significantly associated with both positive outgroup attitudes and greater perceived outgroup variability for both White and Coloured participants (an effect mediated to varying degrees by intergroup anxiety). In Study 2, crossgroup friendships with Coloureds (among White participants) and crossgroup friendships with Whites (among Coloured participants) were significantly associated with positive outgroup attitudes, greater perceived outgroup variability, and lower negative action tendencies toward the respective outgroup (effects mediated to varying degrees by intergroup anxiety and affective empathy).

Caution is urged when comparing the findings of these studies directly, given their differences in methodology (including different mediators, outcomes, and target groups). These differences notwithstanding, it is the similarities of some of the findings across the two studies that are noteworthy and warrant a brief discussion, namely the positive effects of crossgroup friendships on prejudice, and that these effects were consistently stronger for White participants than for Coloured participants. We turn now to a brief discussion of these findings before concluding with a look at some of the limitations of this research, and suggestions for future research.

\section{The Benefits of Crossgroup Friendships}

Crossgroup friendships were associated with reduced intergroup anxiety, increased affective empathy, positive outgroup attitudes, greater perceived outgroup variability, and reduced negative action tendencies. These findings suggest that crossgroup friendships may indeed be important in bringing about improved intergroup relations and intergroup understanding within the South African context, and highlight the central importance of intergroup emotions in the contactprejudice relationship. Together with other South African findings (e.g., Tredoux \& Finchilescu, this issue) the present research reiterates the importance of multicultural educational environments in South Africa as a means for providing individuals from largely racially homogeneous communities with the opportunity for engaging in positive contacts with outgroup members, as such contacts are regularly associated with more positive intergroup emotions and outgroup attitudes (Pettigrew, 1998). Increased opportunities for contact have been shown to be a significant predictor of actual intergroup contact in European studies (e.g., Turner et al., 2007; but see Alexander \& Tredoux, this issue; Dixon \& Durrheim, 2003). 
Although we emphasize the importance of crossgroup friendships, such friendships should not be regarded as essential for the reduction of prejudice as they may be difficult to encourage in a practical way in postconflict societies characterized by continued segregation and limited intergroup interaction (e.g., Durrheim \& Dixon, this issue). Contact quality has, however, a stronger association with reduced prejudice than does contact quantity (e.g., Islam \& Hewstone, 1993; Pettigrew \& Tropp, 2006), and it is this quality contact (embodied in crossgroup friendships) that we emphasize instead.

\section{Contact Effects as a Function of Group Status}

Contact effects were consistently stronger for Whites than for Coloureds across both studies. Substantially larger portions of variance in the outcome measures were explained for the White samples than for the Coloured samples, while a number of the functional relationships expressed in the structural equation models were significantly larger for Whites than for Coloureds. These findings coincide with existing meta-analytic data showing that contact effects are typically stronger for majority- than minority-status groups (Tropp \& Pettigrew, 2005).

Minority- and majority-status groups do not necessarily enter contact settings with the same expectations, nor do they always experience positive contact situations in the same way (Saguy et al., 2008; Tropp, 2006). A fear of being the target of racial prejudice, a heightened awareness of their devalued group status beyond the contact setting, or a sense that the contact experience (irrespective of how positive it may have been) has left the illegitimate status differences beyond the contact setting unaddressed or unaltered (Saguy et al., 2008; Tropp, 2006; Vorauer et al., 1998) are all potential explanations for the relatively weaker contact effects for minority-status Coloureds as compared to majority-status Whites.

The differences in the functional relationships across the two samples were less pronounced in Study 1, where both White and Coloured participants answered questions relating to the Black target group. Whites and Coloureds only differed significantly in the relationship between crossgroup friendships and intergroup anxiety. Although speculative, it is possible that these findings may arise because Coloureds occupy a relative socioeconomic majority status in comparison to the Black outgroup in Stellenbosch, as do the Whites (albeit to a greater extent than the Coloureds).

In effect, therefore, we were possibly comparing the contact effects of two relative majority-status groups interacting with a common minority-status group in Study 1. Under these conditions one would not expect the structural relationships to differ significantly between the two samples. In Study 2, where intergroup interactions were compared between Whites and Coloureds (and vice versa), Coloureds are the relative minority-status group, and therefore the differences in the functional relationships between the White and Coloured participants are more 
pronounced (as predicted by Tropp \& Pettigrew, 2005). However, the substantially lower amounts of explained variance for the Coloured sample in Study 1 suggest that, as in Study 2 (contact with White outgroup members), contact with the Black outgroup has limited benefits for Coloureds as compared to Whites. Thus, although Coloureds may be a relative majority-status group in comparison to Blacks in Stellenbosch, it is possible that the perception of having a devalued political status relative to Black South Africans beyond the contact setting may limit the benefits of the intergroup contact itself. This explanation is speculative, and warrants further investigation.

These differences in contact effects suggest that to the extent that Whites do not experience the contact situation (with Blacks or Coloureds) as threatening to their majority-status position, intergroup contact is likely to improve their outgroup attitudes. The same cannot be said for minority-status Coloureds; as such contact might leave the perception of the relative stability and illegitimacy of the established group hierarchies intact. It seems then, that when structuring intergroup contact experiences aimed at improving intergroup relations (e.g., the contact settings of peace education workshops between groups differing in status; e.g., Salomon, 2004) it is important that they are able to address the status differences between the groups in a manner that does not leave the majority-group members feeling threatened to the extent that it negates any of the benefits of the positive contact setting. The development of both affective empathy and perspective-taking among minority- and majority-status groups in such settings could be instrumental in achieving this (Saguy et al., 2008; Tropp, 2006). Pettigrew's (1998) longitudinal model of contact, in which category salience is gradually introduced into the programs over a period of time, is a potentially useful framework within which such programs may be executed. This being said, it is possible that, while intergroup contact may be effective in reducing prejudice among Whites, changes in the institutionalized status hierarchies that maintain the marginalized status of Coloureds in South Africa are necessary to create an atmosphere where intergroup contact is able to dramatically improve intergroup attitudes among this minority-status group.

\section{The Limitations of This Research}

This research contributes to the contact literature in four ways: (1) it constitutes the first study of its kind within the South African context, replicating findings reported in predominantly European and American settings; (2) it adds to the limited contact literature on affective empathy (as opposed to perspective taking) as a mediator of contact effects; (3) the exploration of the simultaneous effects of affective empathy and intergroup anxiety highlights the specific effects of these two mediators on various outcomes across groups; and (4) the multigroup comparisons add to the limited contact literature in this regard, and support the 
findings of Tropp and Pettigrew (2005) that contact effects are typically stronger for majority- than for minority-status groups.

These contributions notwithstanding, there are four limitations to our research we wish to highlight. First, the contact hypothesis is a causal hypothesis, and this causality cannot be properly examined with cross-sectional studies (MacCallum \& Austin, 2000; but see Pettigrew, 1997; Wagner, Van Dick, Pettigrew, \& Christ, 2003) as seen in the number of equivalent models in both studies. Second, the use of opportunity samples limits the generalizability of the findings. The fact that Black South Africans are underrepresented in the town where this research was undertaken (relative to their national representation), while Coloured and White South Africans are overrepresented, further limits the generalizability of the findings. Third, since the White samples in both studies included only male participants (whereas the Coloured samples included both males and females), the comparative results across the two groups should be considered provisional, contingent upon further studies among White and Coloured males and females. Although metaanalytic findings do not suggest any significant differences in contact effects as a function of gender (see Pettigrew \& Tropp, 2006), the results of studies 1 and 2 were inconsistent in this respect. Finally, our models are unable to account for those unmeasured variables (e.g., perceived status legitimacy; Saguy et al., 2008; Tropp, 2006) that may help to reduce the substantial amounts of unexplained variance (especially among the minority-status Coloured participants).

\section{Directions for Future Research}

Although numerous avenues for future research are suggested by the results of the present research, we highlight only three in light of space limitations. Firstly, future research should explore the potential explanatory variables (e.g., metastereotypes; Vorauer et al., 1998) underlying the substantial differences in contact effects for majority- and minority-status groups in South Africa (see Finchilescu, 2010). Secondly, given the limited intergroup contact in South African society today, it is important to determine whether indirect forms of contact (e.g., extended contact; Wright et al., 1997; also see Turner, Hewstone, Voci, \& Vonofakou, 2008) are able to bring about attitude change and improved intergroup relations. Such indirect contact might be important for preparing individuals for future direct contact by reducing intergroup anxiety (e.g., Paolini et al, 2004; Turner et al., 2007). Finally, longitudinal research in this context (currently under way; see Swart, Hewstone, Christ, \& Voci, 2009) is required to address the causal relationship between putative "predictors" (types of intergroup contact), "mediators," and "outcomes." This would enrich our understanding of the complex and dynamic process of intergroup contact and its effects (Brown \& Hewstone, 2005), and would strengthen the contribution that social psychology can make to the reduction of prejudice in this context. 


\section{References}

Alexander, L., \& Tredoux, C. (2010). The spaces between us: A spatial analysis of informal segregation at a South African university campus. Journal of Social Issues, 66, 369-388.

Allport, G. (1954). The nature of prejudice. Cambridge, MA: Perseus Books.

Amir, Y. (1969). Contact hypothesis in ethnic relations. Psychological Bulletin, 71, 319-342.

Anderson, J. C., \& Gerbing, D. W. (1988). Structural equation modeling in practice: A review and recommended two-step approach. Psychological Bulletin, 103, 411-423.

Baron, R. M., \& Kenny, D. A. (1986). The moderator-mediator variable distinction in social psychological research: Conceptual, strategic, and statistical considerations. Journal of Personality and Social Psychology, 51, 1173-1182.

Batson, C. D., Polycarpou, M. P., Harmon-Jones, E., Imhoff, H. J., Mitchener, E. C., Bednar, L. L., \& Highberger, L. (1997). Empathy and attitudes: Can feeling for a member of a stigmatized group improve feelings toward the group? Journal of Personality and Social Psychology, 72, $105-118$.

Batson, C. D., Turk, C. L., Shaw, L. L., \& Klein, T. R. (1995). Information function of empathic emotion: Learning that we value the other's welfare. Journal of Personality and Social Psychology, $68,1042-1054$.

Brown, R., \& Hewstone, M. (2005). An integrative theory of intergroup contact. In M. Zanna (Ed.), Advances in experimental social psychology (Vol. 37, pp. 255-343). San Diego, CA: Academic Press.

Byrne, B. M., Shavelson, R. J., \& Muthén, B. (1989). Testing for the equivalence of factor covariance and mean structures: The issue of partial measurement invariance. Psychological Bulletin, 105, $456-466$.

Davis, M. H. (1994). Empathy: A social psychological approach. Wisconsin, MA: Brown \& Benchmark

Dixon, J., \& Durrheim, K. (2003). Contact and the ecology of racial division: Some varieties of informal segregation. British Journal of Social Psychology, 42, 1-23.

Dixon, J., Durrheim, K., Tredoux, C., Tropp, L., Clack, B., \& Eaton, E. (2010). A paradox of integration? Interracial contact, prejudice reduction and perceptions of racial discrimination. Journal of Social Issues, 66, 403-418.

Durrheim, K., \& Dixon, J. (2010). Racial contact and change in South Africa. Journal of Social Issues, $66,273-288$.

Finchilescu, G. (2010). Intergroup anxiety in inter-racial interaction: The role of prejudice and metastereotypes. Journal of Social Issues, 66, 335-352.

Galinsky, A. D., \& Moskowitz, G. B. (2000). Perspective-taking: Decreasing stereotype expression, stereotype accessibility, and in-group favoritism. Journal of Personality and Social Psychology, $78,708-724$.

Gibson, J. L. (2004). Overcoming apartheid: Can truth reconcile a divided nation? New York: Russell Sage Foundation.

Grossberg, A. (2002). Race relations. In Human Sciences Research Council, Public attitudes in contemporary South Africa (pp. 63-72). Retrieved January 15, 2007 from http://www.hsrcpress.ac.za/freedownload.asp?id=2025

Hamberger, J., \& Hewstone, M. (1997). Inter-ethnic contact as a predictor of blatant and subtle prejudice: Tests of a model in four West European nations. British Journal of Social Psychology, $36,173-190$.

Hofmeyr, J. H. (2006). Report of the sixth round of the South African Reconciliation Barometer Survey. Retrieved January 10, 2007 from http://www.ijr.org.za/politicalanalysis/ reconcbar/copy_of_sixthroundreportfinal/view

Hu, L., \& Bentler, P. M. (1999). Cutoff criteria for fit indexes in covariance structure analysis: Conventional criteria versus new alternatives. Structural Equation Modeling, 6, $1-$ 55.

Islam, M. R., \& Hewstone, M. (1993). Dimensions of contact as predictors of intergroup anxiety, perceived out-group variability, and out-group attitude: An integrative model. Personality and Social Psychology Bulletin, 19, 700-710. 
Kashima, E. S., \& Kashima, Y. (1993). Perceptions of general variability of social groups. Social Cognition, 11, 1-21.

Levin, S., van Laar, C., \& Sidanius, J. (2003). The effects of ingroup and outgroup friendships on ethnic attitudes in college: A longitudinal study. Group Processes and Intergroup Relations, 6 , $76-92$.

Little, T. D., Cunningham, W. A., Shahar, G., \& Widaman, K. F. (2002). To parcel or not to parcel: Exploring the question, weighing the merits. Structural Equation Modeling, 9, 151173.

MacCallum, R. C., \& Austin, J. T. (2000). Applications of structural equation modeling in psychological research. Annual Review of Psychology, 51, 201-226.

MacCallum, R. C., Wegener, D. T., Uchino, B. N., \& Fabrigar, L. R. (1993). The problem of equivalent models in applications of covariance structure analysis. Psychological Bulletin, 114, 185199.

Mackie, D. M., Devos, T., \& Smith, E. R. (2000). Intergroup emotions: Explaining offensive action tendencies in an intergroup context. Journal of Personality and Social Psychology, 79, 602616.

Mendoza-Denton, R., \& Page-Gould, E. (2008). Can cross-group friendships influence minority students' well-being at historically White universities? Psychological Science, 19, 933-939.

Muthén, L. K., \& Muthén, B. O. (1998-2006). Mplus user's guide (3rd ed.). Los Angeles, CA: Muthén and Muthén.

Page-Gould, E., Mendoza-Denton, R., \& Tropp, L. (2008). With a little help from my cross-group friend: Reducing anxiety in intergroup contexts through cross-group friendship. Journal of Personality and Social Psychology, 95, 1080-1094.

Paolini, S., Hewstone, M., Cairns, E., \& Voci, A. (2004). Effects of direct and indirect cross-group friendships on judgements of Catholics and Protestants in Northern Ireland: The mediating role of an anxiety-reduction mechanism. Personality and Social Psychology Bulletin, 30, 770-786.

Pettigrew, T. F. (1997). Generalized intergroup contact effects on prejudice. Personality and Social Psychology Bulletin, 23, $173-185$.

Pettigrew, T. F. (1998). Intergroup contact theory. Annual Review of Psychology, 49, 65-85.

Pettigrew, T. F., \& Tropp, L. R. (2006). A meta-analytic test of intergroup contact theory. Journal of Personality and Social Psychology, 90, 751-783.

Pettigrew, T. F., \& Tropp, L. R. (2008). How does intergroup contact reduce prejudice? Meta-analytic tests of three mediators. European Journal of Social Psychology, 38, 922-934.

Pillay, N. S., \& Collings, S. J. (2004). Racism on a South African campus: A survey of students' experiences and attitudes. Social Behavior and Personality, 32, 607-618.

Saguy, T., Dovidio, J. F., \& Pratto, F. (2008). Beyond contact: Intergroup contact in the context of power relations. Personality and Social Psychology Bulletin, 43, 432-445.

Salomon, G. (2004). Does peace education make a difference in the context of intractable conflict? Peace and Conflict: Journal of Peace Psychology, 10, 257-274.

Satorra, A., \& Bentler, P. M. (1999). A scaled difference chi-square test statistic for moment structure analysis. Retrieved May 10, 2007 from http://citeseer.ist.psu.edu/314214.html

Sobel, M. E. (1982). Asymptotic confidence intervals for indirect effects in structural equation models. In S. Leinhardt (Ed.), Sociology methodology 1982 (pp. 290-312). Washington, DC: American Sociological Association.

Statistics South Africa (2004). Census 2001: Primary tables South African census '96 and 2001 compared. Retrieved March 7, 2005, from http://www.statssa.gov.za/census01/ html/RSAPrimary.pdf

Stephan, W. G., \& Stephan, C. W. (1985). Intergroup anxiety. Journal of Social Issues, 41, 157-175.

Swart, H., Hewstone, M., Christ, O., \& Voci, A. (2009). Affective mediators of intergroup contact: A longitudinal analysis in South Africa. Manuscript submitted for publication.

Tredoux, C., \& Finchilescu, G. (2010). Mediators of the contact-prejudice relation among South African students on four university campuses. Journal of Social Issues, 66, 289-308.

Tropp, L. R. (2006). Stigma and intergroup contact among members of minority and majority status groups. In S. Levin, \& C. van Laar (Eds.), Stigma and group inequality: Social psychological perspectives (pp. 171-191). Mahwah, N.J.: Lawrence Erlbaum. 
Tropp, L. R., \& Pettigrew, T. F. (2005). Relationships between intergroup contact and prejudice among minority and majority status groups. Psychological Science, 16, 651-653.

Turner, R. N., Hewstone, M., \& Voci, A. (2007). Reducing explicit and implicit prejudice via direct and extended contact: The mediating role of self-disclosure and intergroup anxiety. Journal of Personality and Social Psychology, 93, 369-388.

Turner, R. N., Hewstone, M., Voci, A., Paolini, S., \& Christ, O. (2008). Reducing prejudice via direct and extended cross-group friendship. In W. Stroebe \& M. Hewstone (Eds.), European review of social psychology (Vol. 18, pp. 212-255). Hove, UK: Psychology Press.

Turner, R. N., Hewstone, M., Voci, A., \& Vonofakou, C. (2008). A test of the extended intergroup contact hypothesis: The mediating role of intergroup anxiety, perceived ingroup and outgroup norms, and inclusion of the outgroup in the self. Journal of Personality and Social Psychology, $95,843-860$.

Vandenberg, R. J., \& Lance, C. E. (2000). A review and synthesis of the measurement invariance literature: Suggestions, practices, and recommendations for organizational research. Organizational Research Methods, 3, 4-70.

Vonofakou, C., Hewstone, M., \& Voci, A. (2007). Contact with out-group friends as a predictor of meta-attitudinal strength and accessibility of attitudes toward gay men. Journal of Personality and Social Psychology, 92, 804-820.

Vorauer, J. D., Main, K. J., \& O’Connell, G. B. (1998). How do individuals expect to be viewed by members of lower status groups? Content and implications of metastereotypes. Journal of Personality and Social Psychology, 75, 917-937.

Wagner, U., Van Dick, R., Pettigrew, T. F., \& Christ, O. (2003). Ethnic prejudice in East and West Germany: The explanatory power of intergroup contact. Group Processes and Intergroup Relations, 6, 22-36.

Wright, S. C., Aron, A., McLaughlin-Volpe, T., \& Ropp, S. A. (1997). The extended contact effect: Knowledge of cross-group friendships and prejudice. Journal of Personality and Social Psychology, 73, 73-90.

HERMANN SWART is a Postdoctoral Research Fellow in the Psychology Department at the University of Stellenbosch in South Africa. He earned his DPhil in Social Psychology from Oxford University in 2008. His research interests focus on intergroup contact.

MILES HEWSTONE is Professor of Social Psychology and Fellow of New College, Oxford University. He has published widely on the topics of attribution theory, social cognition, stereotyping, and intergroup relations. His current research focuses on intergroup contact. He is cofounding editor of the European Review of Social Psychology, and a former editor of the British Journal of Social Psychology. He is a Fellow of the British Academy and an Honorary Fellow of the British Psychological Society.

OLIVER CHRIST is a Senior Lecturer for Psychological Methods at the University of Marburg, Germany. He earned his PhD in Social Psychology from Philipps-University, Marburg, Germany in 2005. His research interests lie in the field of intergroup relations, ethnic prejudice, and social identity processes in organizations.

ALBERTO VOCI is Associate Professor of social psychology at the University of Padova, Italy. He completed his $\mathrm{PhD}$ at the same institution in 2000. His 
research concerns the field of prejudice reduction, in particular intergroup contact and empathy, the perceptions of group variability and, more broadly, the relation between motivational and cognitive processes in the dynamic between personal and social identity. He is member of the editorial board of the European Review of Social Psychology. 